УДК 556.166 .4

ЛАНДШАФТЫ НАВОДНЕНИЙ: КОНЦЕПЦИЯ И СПОСОБЫ РАСЧЁТОВ

Напрасников А.Т.

Институт географии им. В.Б. Сочавы СО РАН, Иркутск, е-mail: r.kodar@mail.ru

Обосновывается новый взгляд на истоки проявления наводнений не как случайное кратковременное затопление водами территории, а как ландшафты, формирующие данный процесс. Доказываются двойственные свойства этих геосистем - усиливающее и нейтрализующее динамику водной стихии, соответственно, формирующее и ликвидирующее наводнения. Подобные преобразования характерны для метастабильных ландшафтов. Обладая критической массой, прямыми и обратными связями, они транспортируют и поглощают воды, уменьшают или увеличивают элементы водного баланса. В связи с этим решались следующие задачи: обоснование ландшафтов наводнений, установление структуры их водного баланса и нейтрализация критических величин влаги и тепла, т.е. установление естественного режима ландшафтов наводнений, безопасного для окружающей среды. По информации июньских и июльских катастрофических наводнений 2019 г. в Иркутской области осуществлен географический анализ водно-энергетического баланса ландшафтов - взаимодействие их естественных ресурсов влаги, тепла с внешними критическими притоками и оттоками. Это соответствует понятию ландшафтной иерархии - природные системы и их среды едины. Подобная взаимообусловленность и обеспечила познание ландшафтов наводнений с кратковременными критическими свойствами, определила необходимость создания геосистемного метода расчетов водного и энергетических балансов природных систем с напряжёнными компонентами. Решение задачи осуществлялось совместным анализом климатических, ландшафтных, почвенных и антропогенных факторов. Информационной базой послужили данные уже произошедших наводнений, соответствующие климатические справочники и метод гидролого-климатических расчетов. На этой основе был аргументирован водный баланс ландшафтов наводнений в условиях Восточной Сибири. Таким образом, в работе раскрыта двойственная природа ландшафтов наводнений. Показана необходимость совершенствования региональной концепции водного баланса данных ландшафтов.

Ключевые слова: Иркутская область, ландшафты, наводнение, водный баланс, геоинформационное обеспечение, критические компоненты, влага и тепло

\title{
LANDSCAPES OF FLOODS: THE CONCEPT AND METHODS OF CALCULATIONS
}

Naprasnikov A.T.

V.B. Sochava Institute of Geography SB RAS, Irkutsk, e-mail: r. kodar@mail.ru

We substantiate a new view of the origins of floods not as an accidental short-lasting water flooding of a territory but as landscapes forming this process. We demonstrate the dual properties of these geosystems: the property enhancing or neutralizing the dynamics of water-related emergencies, respectively, and the property forming or eliminating floods. Such transformations are characteristic for metastable landscapes. Having a critical mass and forward and backward linkages, they transport and absorb the waters, and decrease or increase the elements of water balance. In this connection, the following problems were dealt with: substantiating the landscapes of floods, determining the structure of their water balance and neutralizing critical values of moisture and heat, $i$. e. ascertaining the environmentally safe natural regime of landscapes of floods. According to information regarding the June and July 2019 disastrous floods in Irkutsk oblast, a geographical analysis has been made of the water-energy balance of landscapes: the interaction of their natural resources of moisture and heat with external critical inputs and outputs. This corresponds to the notion of the landscape hierarchy - natural systems and their environments are unified. Such an interconditionality provided a more penetrating insight into the landscapes of floods with shortlasting critical properties and dictated a need to develop the geosystem method of calculating the water and energy balances of natural systems with strained components. The problem was solved by making a combined analysis of the climatic, landscape, soil and anthropogenic factors. The information base 1was represented by data on the floods that had occurred already, corresponding the climatic reference books, and by the method of hydrologicalclimatic calculations. On this basis, we determined and demonstrated the water balance of the landscapes of floods in conditions of Eastern Siberia. Thus this study has revealed a dual origin of the landscapes of floods. It is shown that there is a need to improve the regional concept of the water balance of these landscapes.

Keywords: Irkutsk oblast, landscapes, flood, water balance, geoinformation support, critical components, moisture and heat

На грани второго и третьего тысячелетий Российскую Азию потрясли многочисленные разрушения гидротехнических сооружений: Саяно-Шушенская и Бурейская ГЭС, катастрофические наводнение на р. Зея в 2013 г. в Амурской области [1], Тулунское наводнение 2019 г. на р. Ия в Иркутской области. Они сформировались при современном глобальном потепления климата и переходе России на рыночный путь развития [2]. В данных условиях разрушились прежние приоритеты к щадящему обустройству природы и обществу. Капиталистический путь в России его не воспринял, но и не создал альтернативного подхода. В данных условиях имеющийся научный потенциал отечества не смог реализоваться. Опасные наводнения оказались не контролируемыми. При этом свойства наводнений обосновывались прежними статистически- 
ми методами, хотя очевидными стали в их происхождении ландшафтные и антропогенные факторы.

Назрела необходимость учёта, обоснования концепции формирования наводнений и способов их расчета на обширных географических пространствах. Современные знания позволили выстроить иерархическую организацию геосистем, сформулировать статистические связи между их компонентами и режимами. Стало возможным обосновывать системную организацию наводнений в пространственных и временных масштабах.

В связи с этим основной целью работы явилось геосистемное обоснование ландшафтов наводнений как метастабильных состояний с неуравновешенными прямыми и обратными связями.

\section{Результаты исследования и их обсуждение}

Природа ландиафтов наводнения. Природу наводнений увязывают с известными положениями, которые к настоящему времени частично устарели, не всегда соответствуют современным знаниям о природе территории, ее функциях, законах общности её элементов.

Обычно наводнения связывают с климатом. Но это не совсем так, хотя его приоритеты очевидны. Климат приносит влагу и тепло, ландшафт их аккумулирует и распределяет. Между ними устанавливается «трансформатор» - геосистемный преобразователь климатической информации в географическую. У каждого из них свои, но взаимно обусловленные функции.

Всем известно крылатое выражение А.И. Воейкова «реки продукт климата». В этом высказывании просматривается неопределенность. Ведь свойства любых природных систем формирует множество иных, часто не изученных и не предсказуемых явлений. К ним относится и ландшафт. В ландшафте концентрируются все геологические, географические и антропогенные проявления. Они не однозначные, с разными приоритетами, но совместно формирующие ландшафты.

В Иркутской области в конце июня 1919 г. произошла система катастрофических наводнений. Они охватили Тулунский, Нижнеудинский, Тайшетский, Чунский, Зиминский и Куйтунский районы области. В большей степени пострадал г. Тулун. К бедствию такого масштаба никто не был подготовлен.

Современный пространственный и временной анализ наводнений Байкальского ре- гиона и смежных территорий осуществлен Н.В. Кичигиной [3]. Весьма убедительно выявлены причины и следствия их проявлений. Был также осуществлен оперативный научный отклик на наводнения в Иркутской области А.В. Шаликовским с соавторами [4] Ценность данных работ заключается в анализе наводнений системой современных и международных стандартов. Паводок в Иркутской области отмечен в работе [5]. Данные работы содержат ряд практических рекомендаций по предотвращению наводнений, где использовалась климатическая и гидрологическая информация, а географический фактор учитывался, но недостаточно.

Несмотря на отлично выполненные обоснования наводнений в Иркутской области и рекомендации по их предотвращению, остается нерешенным главный вопрос - какая причина сформировавшегося катастрофического наводнения: природа равнины с горным обрамлением или непосредственно ее ландшафты, или антропогенный фактор.

Обычно утверждают, что основной причиной катастрофических наводнений на Иркутско-Черемховской равнине были обильные ливни 25-27 июня. У основания Восточных Саян на станциях Икей и Аршан бассейна реки Ия выпало 218 и 250 мм осадков - более трех месячных норм [5], в г. Тулуне - 85 мм; на станции Хадама бассейна р. Уда выпало 112 мм, в Нижнеудинске 91 мм. Здесь осадки у подножья Восточного Саян формируют наветренные, а городов теневые склоны северных среднегорий.

Данное явление, несколько в иной форме, отмечали А.В. Шаликовский с соавторами: «подъем уровня воды у г. Тулун начался через сутки после начала дождя», «на заполнение очень широких пойм было израсходовано огромное количество воды», «на первую волну паводка, сформированного с водосборной площади вблизи Тулуна, наложилась вторая волна с верховий реки» [4]. Здесь в формирование наводнений вмешался третий важнейший фактор - ландшафт, сконцентрировавший в низинах рельефа критическую массу воды, которая, придя в движение, создала катастрофическое наводнение. Основу данного положения подтверждают следующие природные факторы.

Ландшафты равнины и их горное обрамление обладают общими и разными уникальными свойствами. В геологические времена были заложены единые разломы земной коры Восточных Саян и северных среднегорий - Бирюсинского плато, Ангарского кряжа, Лено-Ангарского плоскогорья. 
Они обеспечили формирование русел современных рек: Бирюсы, Уды, Ия и Оки. Вместе с этим разный рост горных систем сформировал между ними геолого-геоморфологический прогиб, современную Иркутско-Черемховскую равнину. Она не имеет собственной реки, как обычно межгорные долины и котловины, и, соответственно, единого речного стока. На западе ограничена водоразделом между Бирюсой и Удой, на востоке водоразделом между Восточными Саянами и Приморским хребтом. На равнине разгрузка вод происходит исключительно раздельно в пределах бассейновых русел рек, врезанных в северные плоскогорья, нагорья. Равнина замкнута с обеих сторон, что является основной причиной формирования ее климата и наводнений. Этими же причинами определена динамическая инвариантность атмосферных осадков и температур. Все метеорологические станции расположены в пределах 480-550 м абс. высот. В пределах станций средние многолетние месячные атмосферные осадки и температуры разные, но незначительно отличаются друг от друга. Их стандартные отклонения также не значительные. На станциях Тайшет, Алзамай, Ук, Нижнеудинск, Худоеланская, Тулун, Шерагул, Зима, Залари, Черемхово, Усолье и Ангарск существует единое стандартное отклонение осадков и температур, с нормированным пределом изменчивости - 5-10\% относительной погрешности. Имеется и единая связь сумм месячных осадков (X) с месячными температурами (T):

$$
\mathrm{X}=0,09 \mathrm{~T}^{2}+2 \mathrm{~T}+24 ; \mathrm{R}^{2}=0,97 .
$$

Высотные различия станций равнины незначительные. Данный факт позволяет информацию каждой в отдельности метеорологической станции соответствующего бассейна распространять на всю его равнинную площадь.

Показательной является средняя месячная влажность почв в долях наименьшей влагоемкости (V) и ее стандартные отклонения (S).
Средняя влажность почв в июне минимальная. Ее максимум сравнивается с НВ в июле и особенно в августе. Если в июле это обусловлено максимальными осадками, порождающими большое число наводнений, то в августе еще при большей влажности их количество меньшее. Юг региона относится к областям криолитозоны с прерывистой мерзлотой. В долинах рек в конце июля и начале августа мерзлая прослойка полностью протаивает, а весь деятельный слой почв с гидрогеологическим горизонтом поглощает избыточную воду, нейтрализуя формирование наводнений. Но может быть и обратный эффект: мощное излияние вод подмерзлотных таликов в русла рек создаст условия для формирования наводнений. Если мерзлый слой не протаял, то он превращается в водоупор, формирующий наводнения. Двойственные функции почв и глубинных вод являются следствием не уравновешенных в них прямых и обратных связей. Кроме данного явления, климатическую и геолого-геоморфологическую гармонию нарушают сами ландшафты. С увалов атмосферные осадки скатываются в низины, переувлажняют почвы, накапливают воду на земной поверхности, формируют подпрудные озера и болота. В пониженных участках рельефа в пределах 500-560 м абс. высот формируется множество временных и локальных водоемов со слоем воды 50-100 см. Этот водный «аккумулятор» является мощным потенциалом начального проявления наводнений, при котором объединяются все локальные подпрудные водоемы и создают единую движущую силу водных масс. Их не могут освободить суженные русла рек у подножий северных нагорий. Начинают формироваться наводнения. Поэтому при определении составляющих водного баланса в пределах равнины следует иметь в виду наличие двух их видов - баланс вод увалов и низин. На Иркутско-Черемховской равнине заболоченные земли составляют около $25 \%$ площади местных бассейнов.

Таблица 1

Средняя месячная влажность почв (V) в долях наименьшей влагоемкости (HB) и стандартные отклонения (S), определенные за все годы наблюдений на станциях равнины

\begin{tabular}{|l|c|c|c|c|c|c|}
\hline & Июнь & & Июль & & Август & \\
\hline Станция & $\mathrm{V}$ & $\mathrm{S}$ & $\mathrm{V}$ & $\mathrm{S}$ & $\mathrm{V}$ & $\mathrm{S}$ \\
\hline Тулун & 0,78 & 0,18 & 0,9 & 0,22 & 0,93 & 0,21 \\
\hline Нижнеудинск & 0,73 & 0,17 & 0,91 & 0,22 & 0,93 & 0,18 \\
\hline Зима & 0,68 & 0,21 & 0,82 & 0,21 & 0,81 & 0,2 \\
\hline Иркутск & 0,82 & 0,25 & 0,91 & 0,25 & 0,90 & 0,22 \\
\hline
\end{tabular}


Общий потенциал ландшафтной влаги низин увеличивается в разы и превращается в опасное ландшафтное наводнение.

Водный баланс ландшафтов наводнений. Баланс влаги и тепла природных систем - сложнейший процесс. Кроме известных климатических и гидрологических явлений, следует учитывать множество иных факторов: физических, географических, антропогенных и особенно стихийных. Надежными индикаторами наводнений являются атмосферные осадки и сток рек. Но, как уже отмечалось, этого недостаточно.

Прежде всего, следует решить проблему водного баланса кратковременных наводнений. Предлагается эту форму рассматривать в инвариантных системах, в ограниченных пространственных и временных масштабах с надежной информацией. Такой информацией являются месячные значения с конкретным местоположением метеорологической станции. Содержание кратковременной информации о ливнях должно быть тождественно нормированным атмосферным осадкам. Наглядным примером являются максимальные 2\% обеспеченности месячной суммы осадков, пропорциональные суточному максимуму ливней. На равнине их трехмесячная суточная норма равна $2 \%$ месячного максимума осадков:

X 2\% мес. $=2,7$ X 2\% сут. $+1,33 ; \mathrm{R}^{2}=0,99$.

Факт высокой корреляции позволяет водный баланс кратковременных ливней, формирующих наводнения, определять посредством максимально возможного месячного нормированного количества осадков. Это аффинные (родственные) преобразования, что указывает на их природную однородность и единый источник начального формирования.

В дальнейшем водные балансы территории до и после наводнений обосновывались раздельно, а впоследствии объединялись. Месячные максимумы естественных энергетических ресурсов ландшафтов (Е е.л.) рассчитывались по корреляции автора [6].

$$
\begin{aligned}
& \text { Е е.л. }=-0,00001 * \mathrm{t}^{4}+0,0009 * \mathrm{t}^{3}+ \\
& +0,1085 * \mathrm{t}^{2}+3,0124 * \mathrm{t}+27,847,
\end{aligned}
$$

где Е е.л. - месячный водный эквивалент радиационного баланса $(\mathrm{R} / \mathrm{L}=\mathrm{R} / 0,06$ мм); $\mathrm{t}$ - средняя месячная температура воздуха.

Определение энергетических параметров переувлажненных ландшафтов наводнения (Е л.н.), т.е. испарение с достаточно увлажненной почвы или близкой к ней с водной поверхности осуществлялось по кор- реляциям автора с использованием данных Л.И. Зубенок [7]. Выражены они связями месячного испарения с увлажненной поверхности $(\mathrm{E}$ л.н. $=\mathrm{Ro} / \mathrm{L}$ мM) с суммой температур (T) выше $10^{\circ} \mathrm{C}$ : Ro/L(май) $=0,14 \mathrm{~T}+94$; $\mathrm{Ro} / \mathrm{L}($ июнь $)=0,21 \mathrm{~T}+51 ; \quad \mathrm{Ro} / \mathrm{L}($ июль $)=$ $=00,22 \mathrm{~T}+20 ; \quad \mathrm{Ro} / \mathrm{L}($ август $)=0,27 \mathrm{~T}-19 ;$ $\mathrm{Ro} / \mathrm{L}($ сентябрь $)=0,15 \mathrm{~T}+35$. Можно использовать единую, обобщающую корреляцию за любые месячные интервалы:

$$
\mathrm{Ro} / \mathrm{L} \text { мM }=0,21 \mathrm{~T}+31 ; \mathrm{R}^{2}=0,78 .
$$

Однако этими связями не определяется испаряемость с месячной суммой температур менее $400-500^{\circ} \mathrm{C}$. В данных условиях линейные связи (Ro/L) с температурами нарушаются. К северу, в связи с увеличением продолжительности дня, радиационный баланс убывает медленней по сравнению с температурами воздуха.

Факторы, объединяющие водные балансы естественных и ландшафтов наводнений, отражают общность климатических и почвенных составляющих. Особую значимость приобретают почвенные свойства: влажность завядания, наименьшая и полная влагоёмкость. Они отражают граничные и критические условия накопления влаги как в почвенных горизонтах, так и в слоях воды на ландшафтной поверхности - предвестниках наводнений. Подобные явления были отмечены и в других критических состояниях ландшафтов Прибайкалья [8; 9], но с несколько иными характеристиками.

Влажность почв в долях наименьшей влагоёмкости (V) определялась по данным месячных сумм осадков $(\mathrm{X})$ и через средние месячные температуры (t) по связи (3) - характеризующие месячные энергетические ресурсы естественных ландшафтов (Е е.л.):

$$
\mathrm{V}^{\mathrm{r}}=\mathrm{X} / \mathrm{E}_{\text {елл. }} \text { или } \mathrm{V}=\mathrm{r} \sqrt{ } \mathrm{X} / \mathrm{E} \text { е.л. }
$$

Параметр r зависит от структуры почв: для легких он равен: 1,1-1,4; для средних 1,4-2,0; для тяжелых 2,0-3,0 и более.

В мелиоративной практике известно, что любые гидротехнические воздействия преобладающе охватывают метровый слой почвогрунтов. Поэтому все последующие расчеты элементов природных систем ландшафтов осуществлялись для его метрового слоя. Прежде всего, была принята скважность для суглинистых почв, равная 0,45 . Метровый слой почвогрунтов вмещает 450 мм воды, что соответствует его полной влагоёмкости Wп.в., в два раза большей Wн.в. (наименьшей влагоёмкости), равной 220 мм. 
Таблица 2

Критерии формирования наводнений на Иркутско-Черемховской равнине

\begin{tabular}{|l|c|c|c|c|c|c|c|c|c|}
\hline \multicolumn{1}{|c|}{ Станция } & Июнь & & & Июль & & & Август & & \\
\hline & X2\% & V н.в. & $\Delta$ Хс.в. & Х2\% & V н.в. & $\Delta$ X.св. & Х2\% & V н.в. & $\Delta$ Хс.в. \\
\hline Тулун & 124 & 1,14 & 523 & 205 & 1,32 & 1063 & 180 & 1,40 & 1181 \\
\hline Нижнеудинск & 125 & 1,06 & 409 & 187 & 1,27 & 843 & 156 & 1,11 & 563 \\
\hline Зима & 124 & 1,50 & 224 & 218 & 1,41 & 1278 & 152 & 1,17 & 708 \\
\hline
\end{tabular}

Таким образом, определяется вся исходная информация, обеспечивающая формирование геосистем с естественной и экстремальной информацией. Прежде всего рассчитывалась влажность почв за месячные периоды до наступления наводнения и вычислялась в долях наименьшей влагоёмкости $-\mathrm{V}=(\mathrm{X} / \mathrm{E} \text { е.л. })^{0.5}$. Ее количество (W мм) в метровом слое почв определялось: $\mathrm{W}=\mathrm{V} * 220$ мм. Последующие расчеты выполнялись уже для условий переувлажненной почвы, характерной наводнениям, с увлажненной и со слоем воды на ее поверхности. К запасам влаги в почве (W) прибавлялась месячная сумма осадков (X) и вычиталась испаряемость $(\mathrm{Ro} / \mathrm{L})$. Этот баланс влаги считался равным всей площади бассейна в условиях наводнения. Но этот слой воды концентрируется только в четвертой части площади бассейна. Поэтому его увеличивали в четыре раза и затем вычитали всю влагу почв, предполагая, что она равна 450 мм. Именно эта остаточная влага или ее слой на ландшафтной поверхности является фактором формирования наводнений. Данный момент расчетов считается самым слабым звеном в определении водного баланса ландшафтов наводнения. Однако, несмотря на эти допущения, результаты расчетов не противоречат реальным размерам водных потоков наводнений (табл. 2).

В таблицах естественного (Vн.в.) и слоя воды $(\Delta$ Хс.в.) формирования наводнений прослеживается единый признак - влажность почвогрунтов за внутригодовые периоды близка к переувлажнению или к формированию слоя воды на ландшафтной поверхности. Его разгрузка ограничивается суженными руслами рек. Их недостаточная пропускная способность увеличивает слой воды на обширных пространствах бассейна, создаёт повышенный водный напор на смежные комплексы и формирует наводнения.

\section{Заключение}

Определения характеристик ландшафтных наводнений включают статистические приёмы, необходимые для расчета устойчивости инженерных сооружений. Но необходимы и знания иных природных параметров: рельеф ландшафта, скважность, влажность, влагоёмкость почв, гидрологические горизонты, сезонные мерзлые прослойки и многолетние мерзлые породы. Это составляющие физико-географического процесса, на основах которого разработан ландшафтный метод гидролого-климатических расчетов наводнений.

Вырываясь из жестких ландшафтных ограничений, водная стихия становится опасной для существования смежных природных комплексов, элементов окружающих сред, деятельности человека и его жизни. Это инвариантные свойства самой Иркутско-Черемховской равнины, приобретенные за геолого-геоморфологический период ее формирования.

Эти природные опасные явления и породившие их ландшафты следует нейтрализовать. Необходимо построить единую сеть современных мелиоративных систем, которые сохраняли бы в почвогрунтах постоянный недостаток влаги, ниже НB, как поглотитель поступающей извне избыточной влаги. Для этого необходим мониторинг увлажнения почв, предупреждающий наступающее наводнение. Также необходимо совершенствовать региональную концепцию водного баланса ландшафтов наводнения.

\section{Список литературы / References}

1. Махинов А.Н. Основные факторы формирования катастрофических наводнений в бассейне реки Амура в 2013 году // Чтения памяти Владимира Яковлевича Леванидова. Владивосток: Дальнаука, 2014. С. 435-442.

Mahinov A.N. The main factors in the formation of catastrophic floods in the Amur River basin in 2013 // Readings in memory of Vladimir Yakovlevich Levanidov. Vladivostok: Dalnauka, 2014. P. 435-442 (in Russian).

2. Второй оценочный доклад Росгидромета об изменениях климата и их последствиях на территории Российской Федерации. Раздел 1: Наблюдаемые изменения климата. М.: Росгидромет, 2014. С. 18-235.

Roshydromet's second assessment report on climate change and its consequences on the territory of the Russian Federation. Section 1: Observed climate changes. M.: Roshydromet, 2014. P. 18-235 (in Russian). 
3. Кичигина Н.В. Опасность наводнений на реках Байкальского региона // География и природные ресурсы. 2018 № 2. C. 41-51. DOI: 10.21782/GIPR0206-1619-2018-2(41-51)

Kichigina N.V. Flood Hazard on the Rivers of the Baikal Region. Geography and Natural Resources. 2018. V. 39 № 2. C. 120-129. DOI: 10.1134/S187537281802004X.

4. Шаликовский А.В., Лепихин А.П., Тиунов А.А. Курганович К.А., Морозов М.Г. Наводнения в Иркутской области 2019 года // Водное хозяйство России. 2019. № 6 C. 48-65. DOI: 10.35567/1999-4508-2019-6-4.

Shalikovsky A.V., Lepikhin A.P., Tiunov A.A., Kurganovich K.A., Morozov M.G. Floods in the Irkutsk region in $2019 /$ Vodnoye khozyaystvo Rossii. 2019. № 6. P. 48-65 (in Russian).

5. Паводок в Иркутской области побил рекорды за весь период наблюдений // РИА Новости. 08.07.2019. [Электронный ресурс]. URL: https://ria.ru/20190708/1556299303.htm (дата обращения: 10.05.2020)

The flood in the Irkutsk region broke records for the entire observation period // RIA News.07/08/2019. [Electronic resource]. URL: https://ria ru/20190708/1556299303 html (date of access: 10.05.2020) (in Russian)
6. Напрасников А.Т. Геоинформационная и цифровая мелиорация. Иркутск: Изд. ИГУ, 2018. 288 с.

Naprasnikov A.T. Geoinformation and digital land reclamation. Irkutsk: Izd. IGU, 2018. 288 p. (in Russian).

7. Зубенок Л.И. Испарение на континентах. Л.: Изд. Гидрометеоиздат, 1976. 264 с.

Zubenok L.I. Evaporation on the continents. L.: Izd. Gidrometeoizdat, 1976. 264 p. (in Russian).

8. Лапердин В.К., Рыбченко А.А. Оценочные параметры селеформирующих компонентов природной среды юга озера Байкал // Устойчивое развитие горных территорий. 2016. T. 8. № 1. C. 52-58.

Laperdin V.K., Rybchenko A.A. Estimated parameters of seleforming components of the natural environment in the South of lake Baikal // Ustoychivoye razvitiye gornykh territoriy. 2016. V. 8. № 1. P. 52-58 (in Russian).

9. Макаров С.К. Сели Прибайкалья. Иркутск: Изд. Института географии СО РАН, 2012. 111 с.

Makarov S.K. Mudflows in the Baikal region. Irkutsk: Irkutsk: Izd. Instituta geografii SO RAN, 2012. 111 p. (in Russian). 